Check for updates

Cite this: RSC Adv., 2017, 7, 40767

Received 27th June 2017

Accepted 14th August 2017

DOI: 10.1039/c7ra07120e

rsc.li/rsc-advances

\title{
Assessing inter lanthanide photophysical interactions in co-doped titanium dioxide nanoparticles for multiplex assays
}

\author{
Arijita Chakraborty, (D) Gouranga H. Debnath (D) and Prasun Mukherjee (D)*
}

This study assesses the inter lanthanide photophysical interactions in trivalent lanthanide cations $\left(\mathrm{Ln}^{3+}\right) \mathrm{Co}-$ doped titanium dioxide nanoparticles. As a case study, incorporation of neodymium $\left(\mathrm{Nd}^{3+}\right)$ and samarium $\left(\mathrm{Sm}^{3+}\right)$ to generate $\mathrm{Ti}(\mathrm{NdSm}) \mathrm{O}_{2}$ nanoparticles has been considered. The presence of co-doping offers a promising avenue for multiplex assays. The co-doped nanoparticles have characteristic visible emission at 584, 612, 664 and $726 \mathrm{~nm}$ respectively from $\mathrm{Sm}^{3+}$ and near infrared (NIR) emission at 912 and $1094 \mathrm{~nm}$ respectively from $\mathrm{Nd}^{3+}$, thus presenting composite doped nanoparticles with six distinct emission wavelengths spanning both the orange-red and NIR spectral window, using a single excitation wavelength. The photophysical properties of the $\mathrm{Ti}(\mathrm{NdSm}) \mathrm{O}_{2}$ nanoparticles have been compared with that observed in the singly doped $\mathrm{Ti}(\mathrm{Nd}) \mathrm{O}_{2}$ and $\mathrm{Ti}(\mathrm{Sm}) \mathrm{O}_{2}$ nanoparticles. Remarkable differences in the $\mathrm{Ln}^{3+}$ emission have been observed in the singly and doubly doped nanoparticles. Both the $\mathrm{Nd}^{3+}$ and $\mathrm{Sm}^{3+}$ emissions have been found to decrease in the $\mathrm{Ti}(\mathrm{NdSm}) \mathrm{O}_{2}$ nanoparticles, compared to those observed in the singly doped $\mathrm{Ti}(\mathrm{Nd}) \mathrm{O}_{2}$ and $\mathrm{Ti}(\mathrm{Sm}) \mathrm{O}_{2}$ nanoparticles. However, the extent of decrease in emission was found to be unequal for $\mathrm{Nd}^{3+}$ and $\mathrm{Sm}^{3+}$, with a decrease being marginally more prominent in $\mathrm{Nd}^{3+}$. The results have been rationalized by considering the $\mathrm{Ln}^{3+}$ as charge traps in the nanoparticles and associated relaxation pathways that are dictated by the spin selection rule. This photophysical rationalization was further tested and verified by performing experiments with the $\mathrm{Ti}(\mathrm{NdEr}) \mathrm{O}_{2}$ nanoparticles. The results presented provide important physical insight on the design criteria of codoped semiconductor nanoparticles.

\section{Introduction}

The luminescence of trivalent lanthanide cations $\left(\operatorname{Ln}^{3+}\right)$ is gaining increasing attention thanks to the unique characteristics of the core like nature of the $4 \mathrm{f}-4 \mathrm{f}$ transitions and finds use in biological imaging, bio-analytical applications, optoelectronics, telecommunications, lasers, sensing. ${ }^{1-16}$ The $\mathrm{Ln}^{3+}$ luminescence exhibits sharp emission bands spanning entire visible and near infrared (NIR) spectral range with minimum intra and inter $\mathrm{Ln}^{3+}$ spectral overlap, longer lifetime (typically in the range of microseconds to milliseconds), and resistance to photobleaching. These properties offer possibilities for multiplexing, time-gated measurements and longer data acquisition; hence opening up avenues for selective and sensitive detection with better signal to noise ratio.

Development of $\mathrm{Ln}^{3+}$ containing luminophores for practical applications poses challenges because the molar extinction coefficient of $\mathrm{Ln}^{3+}$ is extremely low $\left(\leq 10 \mathrm{M}^{-1} \mathrm{~cm}^{-1}\right.$, as compared to $10^{4}$ to $10^{5} \mathrm{M}^{-1} \mathrm{~cm}^{-1}$ for common organic fluorophores) and

Centre for Research in Nanoscience and Nanotechnology, University of Calcutta, JD-2, Sector-III, Salt Lake, Kolkata-700106, West Bengal, India. E-mail: pmukherjee12@ gmail.com quenching of $\mathrm{Ln}^{3+}$ luminescence by the vibrational overtones of the common bonds present in nearby ligand and solvent molecules. ${ }^{5,17}$ These two factors, namely inefficient direct excitation and efficient environment induced luminescence quenching restrict easy realization of $\mathrm{Ln}^{3+}$ photoluminescence. Placing $\mathrm{Ln}^{3+}$ in an appropriate co-ordination environment with organic molecules as ligands, ${ }^{18-23}$ or incorporating these cations in suitable supramolecular assemblies including dendrimers, micelles, metal organic frameworks (MOF), semiconductor nanoparticles ${ }^{24-41}$ generate important avenues in which usable $\mathrm{Ln}^{3+}$ luminescence could be realized. A beneficial scenario would use placing the $\mathrm{Ln}^{3+}$ in a host matrix that absorbs the electromagnetic radiation efficiently and transfers the energy to the $\mathrm{Ln}^{3+}$ center, thereby realizing the $\mathrm{Ln}^{3+}$ photoluminescence from the composite host-guest system. In addition to the energy feeding process (optical antenna effect) the host matrix protects the $\mathrm{Ln}^{3+}$ luminescence from environmental quenching effects.

Towards the general goal to use $\mathrm{Ln}^{3+}$ photoluminescence for practical applications, we have been working on developing systems with semiconductor nanoparticles as the host, with relevant emphasis on understanding the underlying photophysical processes. ${ }^{38,39,42-47}$ Deciphering the light induced 
processes provide an opportunity to develop novel host (semiconductor nanoparticles)-guest $\left(\operatorname{Ln}^{3+}\right)$ composite system with predictable photoluminescence properties, without necessarily approaching the problem on a combinatorial basis. Recently we have reported a systematic photoluminescence study with $\mathrm{Ln}^{3+}$ $(\mathrm{Ln}=\mathrm{Pr}, \mathrm{Nd}, \mathrm{Sm}, \mathrm{Eu}, \mathrm{Gd}, \mathrm{Tb}, \mathrm{Dy}, \mathrm{Ho}, \mathrm{Er}, \mathrm{Tm}, \mathrm{Yb})$ incorporated $\mathrm{TiO}_{2}\left[\mathrm{Ti}(\mathrm{Ln}) \mathrm{O}_{2}\right]$ nanoparticles and found $\mathrm{Ti}(\mathrm{Nd}) \mathrm{O}_{2}$ and $\mathrm{Ti}(\mathrm{Sm}) \mathrm{O}_{2}$ nanoparticles as the suitable candidates with significant host sensitized $\mathrm{Ln}^{3+}$ emission. ${ }^{46} \mathrm{TiO}_{2}$ nanoparticles were considered as a model system to understand the host sensitized $\mathrm{Ln}^{3+}$ emission, as the ultraviolet-visible spectral region only has contribution from host sensitization, with direct excitation of $\mathrm{Ln}^{3+}$ being generally inefficient and $4 \mathrm{f}-5 \mathrm{~d}$ transition along with the anion valence band to $\mathrm{Ln}^{3+}$ charge transfer (LMCT) energy lying out of the experimentally observed spectral window. The other $\mathrm{Ti}(\mathrm{Ln}) \mathrm{O}_{2}$ [besides $\mathrm{Ti}(\mathrm{Nd}) \mathrm{O}_{2}$ and $\mathrm{Ti}(\mathrm{Sm}) \mathrm{O}_{2}$ ] nanoparticles studied either showed moderate or no host sensitized $\mathrm{Ln}^{3+}$ emission. The luminescence sensitization process has been rationalized considering $\mathrm{Ln}^{3+}$ as the charge (electron and/or hole) traps in the semiconductor nanoparticles and the exciton recombination at these trap sites populating the $\mathrm{Ln}^{3+}$ luminescent energy level, thereby realizing the $\mathrm{Ln}^{3+}$ photoluminescence. It has been observed that in cases where $\mathrm{Ln}^{3+}$ ground and luminescent energy levels are optimally placed within the band gap of the host nanoparticles, the ground and luminescent energy levels of $\mathrm{Ln}^{3+}$ has the capability to trap the hole and electron respectively and such a co-localization of charge carriers in the $\mathrm{Ln}^{3+}$ trap site results in most efficient host sensitized dopant photoluminescence in the $\mathrm{Ti}(\mathrm{Ln}) \mathrm{O}_{2}$ nanoparticles.

Several researchers have investigated assemblies with multiple $\mathrm{Ln}^{3+}$ doping, ${ }^{26,48-58}$ towards the aim to develop multiplex assays which would generally reveal information from different locations in the context of complex diseases. ${ }^{59-65}$ DiMaio and co-workers ${ }^{48}$ have studied controlled energy transfer from $\mathrm{Tb}^{3+}$ to $\mathrm{Eu}^{3+}$ in $\mathrm{LaF}_{3}$ nanoparticles, with spatial restriction of the dopants in either the core or shell in a coreshell nanostructure assembly. Hanley and co-workers ${ }^{49}$ have reported $\mathrm{Sm}^{3+}$ and $\mathrm{Eu}^{3+}$ co-doped silica nanoparticles for multiplexed immunoassays, where inter lanthanide energy transfer was found to be absent. This work further compares a similar system where FITC and Cy3 were co-doped with significant energy transfer from FITC to Cy3, suggesting the usefulness of $\mathrm{Ln}^{3+}$ co-doping to develop multiplex assays. While this study investigates system having lanthanide moieties where inter $\mathrm{Ln}^{3+}$ energy transfer is absent, the study by DiMaio and coworkers $^{48}$ clearly presents a case where such an electronic interaction is relevant; suggesting the importance of $\mathrm{Ln}^{3+}$ identity and their associated interactions in order to develop the co-doped nanoparticles for specific applications. Li and coworkers ${ }^{50}$ labelled silica nanoparticles with $\mathrm{Eu}^{3+}$ and $\mathrm{Tb}^{3+}$ chelates by covalent interaction and used the composite assembly to detect hepatitis B surface antigen (HBsAg) and hepatitis B e antigen (HBeAg) by time-resolved immunofluorometric assays. The use of $\mathrm{Ln}^{3+}$ containing upconversion nanoparticles for multiplexing has been demonstrated by various researchers. ${ }^{51-54}$ Towards the development of near infrared (NIR) luminescent barcodes, Rosi, Petoud and coworkers $^{26}$ reported a metal organic framework (MOF) containing $\mathrm{Er}^{3+}$ and $\mathrm{Yb}^{3+}$ where tunable NIR emission from both the cations are realizable as a function of $\mathrm{Ln}^{3+}$ concentration. Zheng and co-workers ${ }^{55}$ observed either luminescence enhancement or quenching of an $\mathrm{Ln}^{3+}$ in presence of another $\mathrm{Ln}^{3+}$ in co-doped fluoride nanocrystals. Lee and co-workers ${ }^{56}$ developed mixed $\mathrm{Ln}^{3+}(\mathrm{Dy} / \mathrm{Eu}, \mathrm{Ho} / \mathrm{Eu}, \mathrm{Ho} / \mathrm{Tb})$ oxide nanoparticles for dual applications in magnetic resonance imaging (MRI) and photoluminescence imaging. Other researchers have also reported the use of lanthanide containing systems for multiplexing in biological assays. ${ }^{57,58}$ These studies collectively indicate that developing co-doped $\mathrm{Ln}^{3+}$ nanoparticles with simultaneous realization of distinct non-overlapping emission provide an avenue in the perspective of multiplex assays. Thus understanding and optimizing the inter lanthanide photophysical interactions is necessary.

While our previous works ${ }^{38,46,47}$ provide a foundation to rationalize the photophysical processes in singly $\mathrm{Ln}^{3+}$ incorporated semiconductor nanoparticles; these studies do not address the interactions in the cases of co-doping. Unravelling the photophysical interactions between $\mathrm{Ln}^{3+}$ of different identity is the primary objective of this study, where one $\mathrm{Ln}^{3+}$ may result in photoluminescence brightening or quenching of the other $\mathrm{Ln}^{3+}$ moiety. This study is organized as follows. The optimum extent of co-doping has been identified first by varying the $\mathrm{Nd}^{3+}$ and $\mathrm{Sm}^{3+}$ nominal doping extent in the $\mathrm{Ti}(\mathrm{NdSm}) \mathrm{O}_{2}$ nanoparticles. The choice of $\mathrm{Nd}^{3+}$ and $\mathrm{Sm}^{3+}$ as co-dopants is based on our observation of significant host sensitized $\mathrm{Ln}^{3+}$ emission in the $\mathrm{Ti}(\mathrm{Ln}) \mathrm{O}_{2}[\mathrm{Ln}=\mathrm{Nd}, \mathrm{Sm}]$ nanoparticles, compared to the other $\mathrm{Ti}(\mathrm{Ln}) \mathrm{O}_{2}$ systems. ${ }^{46}$ This follows structural analysis of $\mathrm{Ti}(\mathrm{NdSm}) \mathrm{O}_{2}$ nanoparticles by X-ray diffraction (XRD) and Fourier transform infrared (FTIR) spectroscopy, corresponding comparisons with the singly doped $\mathrm{Ti}(\mathrm{Nd}) \mathrm{O}_{2}$ and $\mathrm{Ti}(\mathrm{Sm}) \mathrm{O}_{2}$ nanoparticles have been made. Photophysical properties have been studied in the appropriate doubly $\left[\mathrm{Ti}(\mathrm{NdSm}) \mathrm{O}_{2}\right.$ and $\mathrm{Ti}(\mathrm{NdEr}) \mathrm{O}_{2}$ (vide infra)] doped nanoparticles, with relevant comparisons with the singly $\left[\mathrm{Ti}(\mathrm{Nd}) \mathrm{O}_{2}, \mathrm{Ti}(\mathrm{Sm}) \mathrm{O}_{2}\right.$ and $\left.\mathrm{Ti}(\mathrm{Er}) \mathrm{O}_{2}\right]$ doped systems. Finally, an analysis is provided to rationalize the experimental observations.

\section{Materials and methods}

\section{Chemicals}

Tetra( $n$-butyl)titanate and lanthanide acetate hydrates ( $\mathrm{Ln}=$ Nd, Sm, Er) (99.9\%) were purchased from Alfa Aesar. Ethanol was purchased from Merck. IR grade potassium bromide (KBr) was purchased from Sigma-Aldrich. All chemicals were used as purchased without additional purification. Water used in all experiments was obtained from a Millipore system with a resistivity of $18.2 \mathrm{M} \Omega \mathrm{cm}$ at $25^{\circ} \mathrm{C}$.

\section{Nanoparticle synthesis}

The general synthetic protocol was adopted from the reports by Chen and co-workers ${ }^{66,67}$ and our previous work, ${ }^{46}$ which was further modified for the co-doping i.e. multiple distinct 
lanthanide incorporation within a single nanoparticle. For the synthesis of $\mathrm{Ti}(\mathrm{NdSm}) \mathrm{O}_{2}$ nanoparticles with nominal doping extent of $2 \%$ in each $\mathrm{Ln}^{3+}, 58 \mu \mathrm{mol}$ of each lanthanide (Ln: $\mathrm{Nd}$ and $\mathrm{Sm}$ )(III) acetate hydrate salt were dissolved in $200 \mu \mathrm{l}$ water and $20 \mathrm{ml}$ absolute ethanol with stirring at room temperature. $1 \mathrm{ml}$ of tetra(n-butyl)titanate, dissolved in $20 \mathrm{ml}$ ethanol was added to the previous mixture and stirring was continued with a magnetic stirrer for three hours. The resultant cloudy mixture was transferred to $50 \mathrm{ml}$ Teflon lined autoclave to undergo the solvothermal treatment for 5 hours at $120^{\circ} \mathrm{C}$. The mixture was allowed to cool to room temperature. The as-synthesized materials were washed using absolute ethanol several times followed by centrifugation. The obtained precipitates were dried overnight at $60^{\circ} \mathrm{C}$. The sample was annealed at $500{ }^{\circ} \mathrm{C}$ for 2 hours. The syntheses of the $\mathrm{Ti}(\mathrm{NdSm}) \mathrm{O}_{2}$ nanoparticles with nominal doping extent of $1 \%$ and $4 \%$ in each $\mathrm{Ln}^{3+}$ were performed with $29 \mu \mathrm{mol}$ and $0.116 \mathrm{mmol}$ of each $\mathrm{Ln}^{3+}$ respectively, with the other conditions in the syntheses remaining same. The $\mathrm{Ti}(\mathrm{NdEr}) \mathrm{O}_{2}$ nanoparticles were synthesized with $2 \%$ nominal doping extent in each $\mathrm{Ln}^{3+}$ using the same synthetic procedure, with the incorporation of appropriate $\mathrm{Ln}^{3+}$ precursors.

\section{X-ray diffraction}

X-ray powder diffraction pattern of the samples were collected by using a PANalytical X'pert PRO diffractometer, operated at a generator voltage of $40 \mathrm{kV}$ and current of $30 \mathrm{~mA}$ with $\mathrm{Cu} \mathrm{K \alpha}$ radiation $(\lambda=0.154 \mathrm{~nm})$ within the $2 \theta$ scan range of $15^{\circ}$ to $90^{\circ}$.

\section{Fourier transform infrared spectroscopy}

Fourier transform infrared spectra were acquired using Jasco FTIR 6300 spectrometer. The spectra presented were collected from an average of 64 scans. During spectral acquisition, the resolution was maintained at $4 \mathrm{~cm}^{-1}$. The sample for the experiment was prepared using $\mathrm{KBr}$ pellet method. The spectra were recorded at room temperature. The data analysis was carried out using the software provided with the instrument.

\section{Electron microscopy measurements}

The transmission electron microscopy (TEM) experiments were performed to identify the morphology of the sample by using TEM instrument from JEOL (model JEM-2100) operated with an acceleration potential of $200 \mathrm{kV}$. The sample was prepared by placing a drop of colloidal dispersion on a carbon coated copper grid. Extra sample was removed by drying the grid. The energy dispersive X-ray spectra (EDS) were acquired using the Zeiss model EVO 18 scanning electron microscopy instrument.

\section{Luminescence spectroscopy}

The steady-state luminescence spectra were acquired in the Horiba Fluorolog 3-22 luminescence spectrometer. To obtain the emission spectra, samples were excited at $350 \mathrm{~nm}$ and the excitation spectra were acquired by monitoring the major emission bands. To collect the spectra in visible region, the excitation and emission slits were kept at $2 \mathrm{~nm}$ spectral resolution. In the case of NIR spectral region, excitation and emission slits were maintained at $8 \mathrm{~nm}$ and $4 \mathrm{~nm}$ spectral resolutions respectively. For the samples with low luminescence intensity in the visible region, the spectra were acquired with $4 \mathrm{~nm}$ spectral resolution for both the excitation and emission slits. In the NIR spectral window, the excitation and emission spectral resolutions were maintained at $14 \mathrm{~nm}$ and $40 \mathrm{~nm}$ respectively for the samples with low luminescence intensity. For photoluminescence lifetime measurements a delay time and detection window of 0.5 and $5 \mathrm{~ms}$ respectively were used for the nanoparticles and the corresponding values were kept at 0.0001 and $0.05 \mathrm{~ms}$ respectively for collecting the emission from Sm(III) acetate. For lifetime measurements, the nanoparticles were excited at $350 \mathrm{~nm}$ and the emission was collected at $612 \mathrm{~nm}$. The excitation and emission wavelengths for collection of Sm(III) acetate lifetime were kept at 400 and $595 \mathrm{~nm}$ respectively. The lifetimes were fitted with sum of two decaying exponentials. All data analyses were performed using Origin 8.5 software. To collect the emission in the visible and NIR spectral region the R928 photomultiplier tube (PMT) and a liquid nitrogen cooled indium gallium arsenide (InGaAs) detector [model DSSIGA(1-9) 010L] were used, respectively. The nanoparticles were dispersed in water for the photoluminescence measurements. All measurements were performed at ambient conditions.

The photoluminescence quantum yields for the $\mathrm{Ln}^{3+}$ luminescence in the visible spectral range were calculated based on a relative method with a comparison to the quantum yield of coumarin 153 (C153) dissolved in methanol $\left(\Phi_{\mathrm{r}}=0.42\right.$ (ref. 68)). Relative quantum yields $\Phi_{\mathrm{x}}$ with all the experimentally observed $\mathrm{Ln}^{3+}$ emission bands were calculated using eqn (1);

$$
\frac{\Phi_{\mathrm{x}}}{\Phi_{\mathrm{r}}}=\frac{A_{\mathrm{r}}\left(\lambda_{\mathrm{r}}\right) I_{\mathrm{ex}}\left(\lambda_{\mathrm{r}}\right) \eta_{\mathrm{x}}{ }^{2} \int_{0}^{\infty} I_{\mathrm{em}, \mathrm{x}}(\bar{\nu}) \mathrm{d} \bar{\nu}}{A_{\mathrm{x}}\left(\lambda_{\mathrm{x}}\right) I_{\mathrm{ex}}\left(\lambda_{\mathrm{x}}\right) \eta_{\mathrm{r}}{ }^{2} \int_{0}^{\infty} I_{\mathrm{em}, \mathrm{r}}(\bar{\nu}) \mathrm{d} \bar{\nu}}
$$

where the subscripts $\mathrm{x}$ and $\mathrm{r}$ stand for sample and reference respectively, $A$ is the absorbance at the excitation wavelength $(\lambda)$, $I_{\mathrm{ex}}$ is the intensity of the excitation light at the same wavelength, $\eta$ is the refractive index $(\eta=1.333$ for water and $\eta=1.327$ for methanol) and $I_{\mathrm{em}}(\bar{\nu})$ is the luminescence intensity as a function of wavenumber $\bar{\nu}$. For the calculation of relative quantum yields in the NIR spectral region for the $\mathrm{Nd}^{3+}$ and $\mathrm{Er}^{3+}$ emission bands, the PMT and InGaAs detectors were calibrated with respect to the common band of $\mathrm{Tm}^{3+}$ emission in the $\mathrm{Ti}(\mathrm{Tm}) \mathrm{O}_{2}$ nanoparticles which is centered around $810 \mathrm{~nm}^{.6}$

\section{Results and discussion}

\section{$\mathrm{X}$-ray diffraction}

The X-ray diffraction patterns of the $\mathrm{Ti}(\mathrm{Nd}) \mathrm{O}_{2}, \mathrm{Ti}(\mathrm{Sm}) \mathrm{O}_{2}$ and $\mathrm{Ti}(\mathrm{NdSm}) \mathrm{O}_{2}$ nanoparticles are shown in Fig. 1. For the doubly doped system, a nominal doping extent of $2 \%$ in each $\mathrm{Ln}^{3+}$ has been considered (vide infra). The singly doped nanoparticles show characteristic diffraction peaks at $2 \theta=25.4,38.0,48.3$, $54.2,55.3,62.7,69.1,70.4$ and 75.4 that has been correlated with the (101), (004), (200), (105), (211), (204), (116), (220) and (215) planes of anatase $\mathrm{TiO}_{2}$ crystal respectively. The nanoparticles with both $\mathrm{Nd}^{3+}$ and $\mathrm{Sm}^{3+}$ co-doped also exhibit similar 


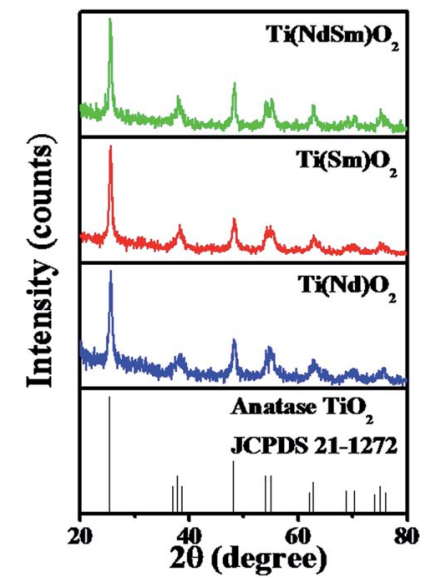

Fig. 1 XRD profiles of the $\mathrm{Ti}(\mathrm{Nd}) \mathrm{O}_{2}, \mathrm{Ti}(\mathrm{Sm}) \mathrm{O}_{2}$ and $\mathrm{Ti}(\mathrm{NdSm}) \mathrm{O}_{2}$ nanoparticles are shown.

diffraction pattern indicating that the crystal structure remains unchanged in the doubly doped $\mathrm{TiO}_{2}$ nanoparticles. Moreover, in all the nanoparticles studied, characteristic peak at $2 \theta=27.4$ from the (110) plane of the rutile phase was absent, suggesting that rutile phase does not have contribution in the systems investigated in the present work.

To this end, we comment on the possible presence of the lanthanide impurity phases in the observed XRD patterns. For this exercise, a comparison of intensities has been made at $2 \theta=$ $65^{\circ}$ (taken as a representative case), where no signal is present in the XRD patterns of either $\mathrm{Ti}(\mathrm{Ln}) \mathrm{O}_{2}[\mathrm{Ln}=\mathrm{Nd}, \mathrm{Sm}]$, Ti $(\mathrm{NdSm})$ $\mathrm{O}_{2}$ nanoparticles [as judged from the Joint Committee on Powder Diffraction Standards (JCPDS) card 21-1272] and the lanthanide impurity phases (as judged from the following JCPDS cards) with the corresponding intensity at the position of most intense lines of various lanthanide impurity phases, as mentioned in the parentheses, of neodymium oxide [JCPDS card numbers 65-6729 $\left(\mathrm{Nd}_{2} \mathrm{O}_{3}\right.$, hexagonal, $\left.2 \theta=30.8^{\circ}\right)$, 65-3184 $\left(\mathrm{Nd}_{2} \mathrm{O}_{3}\right.$, cubic, $\left.2 \theta=28.0^{\circ}\right), 46-1074\left(\mathrm{NdO}_{2}\right.$, cubic, $\left.2 \theta=28.0^{\circ}\right), 45-$ $0087\left(\mathrm{Nd}_{6} \mathrm{O}_{11}\right.$, cubic, $\left.2 \theta=28.0^{\circ}\right)$ ], $\mathrm{Nd}_{x} \mathrm{Ti}_{y} \mathrm{O}_{z}$ [JCPDS cards 82$1095\left(\mathrm{Nd}_{2} \mathrm{Ti}_{3} \mathrm{O}_{9}\right.$, tetragonal, $\left.2 \theta=29.6^{\circ}\right), 70-2294\left(\mathrm{NdTiO}_{3}\right.$, orthorhombic, $\left.2 \theta=32.4^{\circ}\right), 70-1691\left(\mathrm{Nd}_{2} \mathrm{Ti}_{2} \mathrm{O}_{7}\right.$, monoclinic, $2 \theta=$ $\left.30.3^{\circ}\right), 70-1544\left(\mathrm{Nd}_{2} \mathrm{TiO}_{5}\right.$, orthorhombic, $\left.2 \theta=28.6^{\circ}\right), 40-1051(\alpha-$ $\left.\mathrm{Nd}_{2} \mathrm{Ti}_{4} \mathrm{O}_{11}, 2 \theta=51.2^{\circ}\right)$ ], samarium oxide [JCPDS cards 65-3183 $\left(\mathrm{Sm}_{2} \mathrm{O}_{3}\right.$, cubic, $\left.2 \theta=28.3^{\circ}\right), 43-1030\left(\mathrm{Sm}_{2} \mathrm{O}_{3}\right.$, monoclinic, $2 \theta=$ $32.0^{\circ}$ ), 33-1146 (SmO, cubic, $\left.2 \theta=31.3^{\circ}\right)$ ] and $\mathrm{Sm}_{x} \mathrm{Ti}_{y} \mathrm{O}_{z}$ [JCPDS cards 70-2295 $\left(\mathrm{SmTiO}_{3}\right.$, orthorhombic, $\left.2 \theta=32.4^{\circ}\right), 47-0283$ $\left(\mathrm{Sm}_{2} \mathrm{Ti}_{2} \mathrm{O}_{7}\right.$, orthorhombic, $\left.2 \theta=30.5^{\circ}\right)$, 41-0497 $\left(\mathrm{Sm}_{4} \mathrm{Ti}_{3} \mathrm{O}_{12}\right.$, monoclinic, $\left.2 \theta=27.5^{\circ}\right), 22-1306\left(\mathrm{Sm}_{2} \mathrm{TiO}_{5}\right.$, orthorhombic, $2 \theta=$ $\left.29.0^{\circ}\right)$, 35-0364 $\left(\beta-\mathrm{Sm}_{2} \mathrm{TiO}_{5}\right.$, hexagonal, $\left.\left.2 \theta=31.7^{\circ}\right)\right]$. These intensities are comparable in magnitude, necessarily reflecting noise in the observed XRD patterns where supposed lanthanide impurity phases should appear; suggesting that the observed signals from the nanoparticles studied do not have significant contribution from the lanthanide impurity phases.

\section{Fourier transform infrared (FTIR) spectroscopy}

The FTIR spectra of the $\mathrm{Ti}(\mathrm{Nd}) \mathrm{O}_{2}, \mathrm{Ti}(\mathrm{Sm}) \mathrm{O}_{2}$ and $\mathrm{Ti}(\mathrm{NdSm}) \mathrm{O}_{2}$ nanoparticles are shown in Fig. 2. For the doubly doped

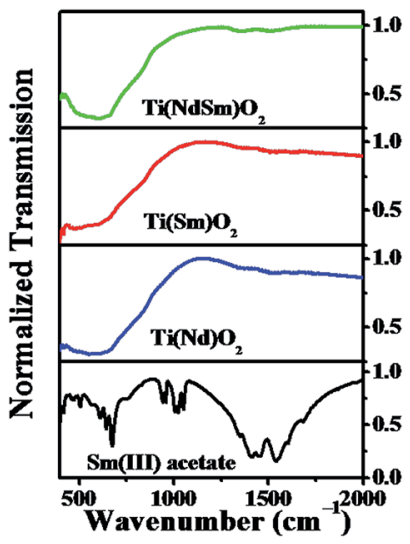

Fig. 2 FTIR spectra of the $\mathrm{Ti}(\mathrm{Nd}) \mathrm{O}_{2}, \mathrm{Ti}(\mathrm{Sm}) \mathrm{O}_{2}$ and $\mathrm{Ti}(\mathrm{NdSm}) \mathrm{O}_{2}$ nanoparticles are shown. The corresponding spectra of Sm(II) acetate is also included.

nanoparticles, a nominal doping extent of $2 \%$ in each $\mathrm{Ln}^{3+}$ has been considered (vide infra). All the nanoparticles investigated show characteristic infrared absorption bands at $470-490$ and $660 \mathrm{~cm}^{-1}$ respectively, a signature of Ti-O-Ti bond vibrations. A comparison with the corresponding spectrum of Sm(III) acetate clearly reveals a different spectral signature, with characteristic bands at 1550 and $1460 \mathrm{~cm}^{-1}$ respectively originating from the carboxylate asymmetric and symmetric stretching vibrations. The absence of these bands in the nanoparticles investigated clearly indicates the absence of significant amount of free $\mathrm{Ln}(\mathrm{III})$ precursor salt in the nanoparticles studied and the $\operatorname{Ln}($ III) related spectral signature being originated from the $\operatorname{Ln}(\mathrm{III})$ moieties that has interacted with the nanoparticles (vide infra).

\section{Electron microscopy}

The transmission electron microscopy (TEM) image of the $\mathrm{Ti}(\mathrm{NdSm}) \mathrm{O}_{2}$ nanoparticles is shown in Fig. 3. The particles were found to be spherical in nature with the corresponding size distribution revealing a diameter of $2.6 \pm 0.5 \mathrm{~nm}$, reported as the average and standard deviation values. Our previous work ${ }^{46}$ reports a particle diameter of $3.5 \pm 0.4 \mathrm{~nm}$ for the $\mathrm{Ti}(\mathrm{Sm}) \mathrm{O}_{2}$ nanoparticles. This suggests that co-doping $\mathrm{Nd}^{3+}$ and $\mathrm{Sm}^{3+}$ in the $\mathrm{TiO}_{2}$ nanoparticles do not affect the particle morphology to a significant extent. The high resolution transmission electron microscopy (HRTEM) image and the selected area electron diffraction (SAED) pattern identify the crystalline phases in the nanoparticles. The energy dispersive X-ray spectra (EDS) of the nanoparticles studied clearly identify the characteristic elemental peaks.

Incorporation of $\mathrm{Ln}^{3+}$ in $\mathrm{TiO}_{2}$ nanoparticles generates lattice distortion and charge compensation, which is guided by the size and charge mismatch between the cationic ingredients. In a case study with europium doped titanium dioxide $\left[\mathrm{Ti}(\mathrm{Eu}) \mathrm{O}_{2}\right]$ nanoparticles Chen and co-workers ${ }^{66}$ identified three distinct $\mathrm{Eu}^{3+}$ related sites in which for the two core sites the local site symmetry of $\mathrm{Ti}^{4+}$ deviates from $D_{2 \mathrm{~d}}$ to $D_{2}$ and $C_{2 \mathrm{v}}$ symmetry and one surface related site with $C_{1}$ symmetry. 

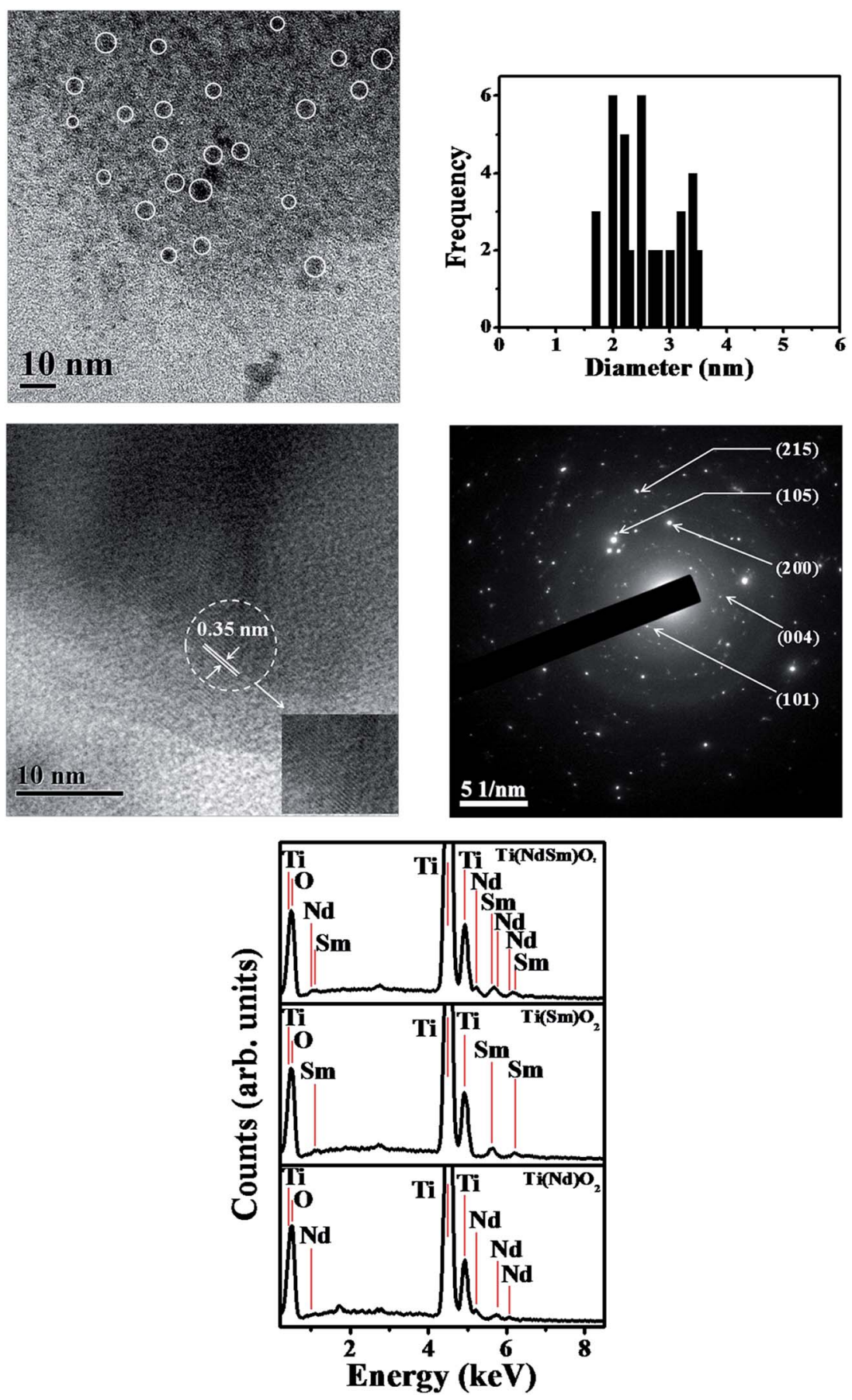

Fig. 3 TEM image of the $\mathrm{Ti}(\mathrm{NdSm}) \mathrm{O}_{2}$ nanoparticles is shown in the top left panel, with the corresponding size distribution shown in the top right panel. The middle left and right panels show the HRTEM image and SAED pattern respectively. The bottom panel shows the EDS of various nanoparticles studied.

\section{Photoluminescence spectroscopy}

Doping extent. The development of $\mathrm{Nd}^{3+}$ and $\mathrm{Sm}^{3+}$ co-doped $\mathrm{TiO}_{2}\left[\mathrm{Ti}(\mathrm{NdSm}) \mathrm{O}_{2}\right]$ nanoparticles require optimizing the dopant amounts in order to realize appreciable emission from both the lanthanide cations, so that the resultant co-doped nanoparticles benefit from both $\mathrm{Sm}^{3+}$ visible and $\mathrm{Nd}^{3+}$ near infrared (NIR) emission respectively. Towards this goal, we have attempted to synthesize the co-doped nanoparticles with $1 \%, 2 \%$ and $4 \%$ in each of the $\mathrm{Ln}^{3+}$ and the photoluminescence emission spectra of all these nanoparticles were acquired. The summary of a comparative account of the dopant emission in the co-doped nanoparticles with varying dopant extent is presented in Fig. 4. A visual inspection clearly reveals increased contribution from both $\mathrm{Nd}^{3+}$ and $\mathrm{Sm}^{3+}$ emission in the $\mathrm{Ti}(\mathrm{NdSm}) \mathrm{O}_{2}$ nanoparticles with nominal doping extent of $2 \% \mathrm{Nd}^{3+}$ and $2 \% \mathrm{Sm}^{3+}$ respectively. The corresponding cases with $1-1 \%$ and $4-4 \%$ co-dopant 

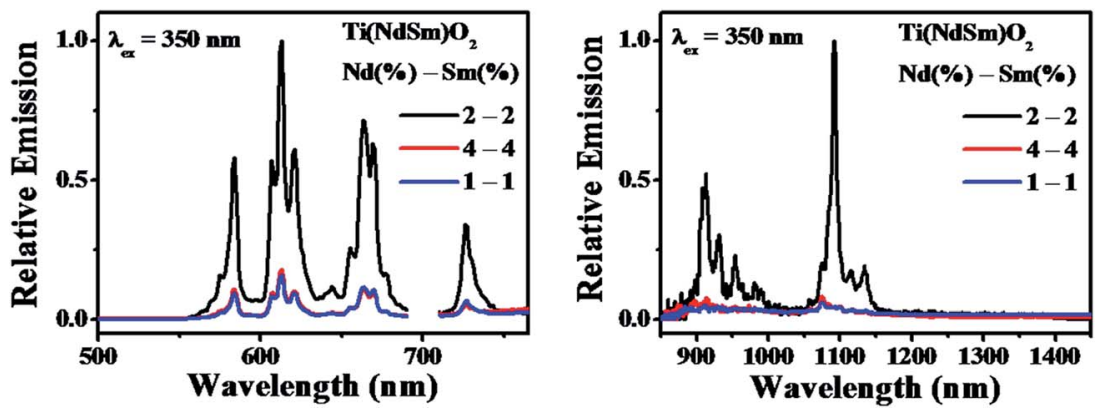

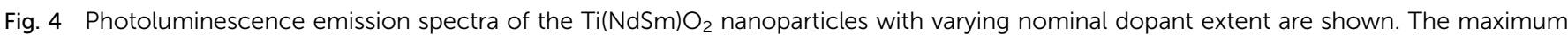
intensity of the $\mathrm{Sm}^{3+}$ (left panel) and $\mathrm{Nd}^{3+}$ (right panel) emission of the sample with nominal doping extent of $2 \%$ in each $\mathrm{Ln}^{3+}$ has been normalized to unity in each panel, with the other spectra shown with respect to the intensity of this spectrum.

exhibit dramatically reduced $\mathrm{Ln}^{3+}$ emission. Consequently, further characterization towards the development of co-doped nanoparticles in this work was focused with the system containing $2 \% \mathrm{Nd}^{3+}$ and $2 \% \mathrm{Sm}^{3+}$ respectively, as the nominal doping extent.

It might be intuitively argued that the decreased luminescence intensity in the co-doped nanoparticles with nominal doping extent of $1 \%$ in each $\mathrm{Ln}^{3+}$ is associated with the lower amount of $\mathrm{Ln}^{3+}$ being present in the nanoparticles. The corresponding case with $4 \%$ in each $\mathrm{Ln}^{3+}$ poses an interesting case, where it demonstrates that merely increasing the doping extent does not make the dopant emission brighter. This could either originate from the inefficiency of dopant incorporation in the nanoparticles beyond a certain limit or due to the introduction of additional non-radiative decay pathways induced by high local dopant concentration. Important insight on this aspect comes from the elemental composition obtained from EDS measurements. The elemental composition for the nanoparticles studied is summarized in Table 1 . These data reveal an increase in the amount of both $\mathrm{Nd}^{3+}$ and $\mathrm{Sm}^{3+}$ in the $\mathrm{Ti}(\mathrm{NdSm})$ $\mathrm{O}_{2}$ nanoparticles as a function of dopant concentration, suggesting the difficulty to explain the dopant luminescence quenching in the $4-4 \%$ co-doping case originating from inefficiency of dopant incorporation. Correspondingly, we propose that the luminescence quenching in this case most likely associate with the introduction of additional non-radiative decay paths that is correlated with high local concentration of the dopant cations.
Comparison of photoluminescence between singly and doubly doped nanoparticles. Fig. 5 summarizes a comparison of photoluminescence spectra of the $\mathrm{Ti}(\mathrm{Nd}) \mathrm{O}_{2}, \mathrm{Ti}(\mathrm{Sm}) \mathrm{O}_{2}$ and $\mathrm{Ti}(\mathrm{NdSm}) \mathrm{O}_{2}$ nanoparticles dispersed in water. Exciting the $\mathrm{Ti}(\mathrm{Nd}) \mathrm{O}_{2}$ nanoparticles with $350 \mathrm{~nm}$ radiation show characteristic $\mathrm{Nd}^{3+}$ emission bands at 912, 1094 and $1350 \mathrm{~nm}$ that originates from the ${ }^{4} \mathrm{~F}_{3 / 2} \rightarrow{ }^{4} \mathrm{I}_{n}[n=9 / 2-13 / 2]$ transitions respectively. Similar experiments with the $\mathrm{Ti}(\mathrm{Sm}) \mathrm{O}_{2}$ nanoparticles has emission bands located at 584, 612, 664 and $726 \mathrm{~nm}$. These transitions originate from the ${ }^{4} \mathrm{G}_{5 / 2} \rightarrow{ }^{6} \mathrm{H}_{n}[n=$ 5/2-9/2] transitions respectively. Monitoring either the $\mathrm{Nd}^{3+}$ emission at $1094 \mathrm{~nm}$ in the $\mathrm{Ti}(\mathrm{Nd}) \mathrm{O}_{2}$ or the $\mathrm{Sm}^{3+}$ emission at $612 \mathrm{~nm}$ in the $\mathrm{Ti}(\mathrm{Sm}) \mathrm{O}_{2}$ nanoparticles gives rise to a broad excitation profile that is centered around $350 \mathrm{~nm}$ without visible contribution from direct sharp intra-configurational $4 \mathrm{f}-4 \mathrm{f}$ excitation transitions, suggesting an optical antenna effect being operative to sensitize the $\mathrm{Nd}^{3+}$ and $\mathrm{Sm}^{3+}$ emission in the $\mathrm{Ti}(\mathrm{Ln}) \mathrm{O}_{2}[\mathrm{Ln}=\mathrm{Nd}, \mathrm{Sm}]$ nanoparticles. These observations are consistent with our previous report. ${ }^{46}$

The nanoparticles with both $\mathrm{Nd}^{3+}$ and $\mathrm{Sm}^{3+}$ co-doped $\left[\mathrm{Ti}(\mathrm{NdSm}) \mathrm{O}_{2}\right]$ show characteristic emission bands from both the $\mathrm{Nd}^{3+}$ and $\mathrm{Sm}^{3+}$, giving access to both visible and near infrared (NIR) emission simultaneously with a single excitation source. Moreover, the emission lines are distinct due to core like feature of the $4 \mathrm{f}-4 \mathrm{f}$ transitions and do not have inter-band overlap. Thus the $\mathrm{Ti}(\mathrm{NdSm}) \mathrm{O}_{2}$ nanoparticles gives rise to six distinct emission bands, benefiting towards its usefulness as multiplex assays. Additionally, as the realization of $\mathrm{Ln}^{3+}$ photoluminescence has been achieved by host sensitization and not

Table 1 Extent of doping in the $\mathrm{Ti}(\mathrm{NdSm}) \mathrm{O}_{2}$ nanoparticles with varying dopant extent ${ }^{a}$

\begin{tabular}{|c|c|c|c|c|c|}
\hline$\left[\mathrm{Nd}^{3+}\right]\left(\right.$ nominal) ${ }^{b}$ & {$\left[\mathrm{Sm}^{3+}\right](\text { nominal })^{b}$} & {$[\mathrm{Nd}](\mathrm{EDS})^{c}$} & {$[\mathrm{Sm}](\mathrm{EDS})^{c}$} & {$[\mathrm{Ti}](\mathrm{EDS})^{c}$} & {$[\mathrm{O}](\mathrm{EDS})^{c}$} \\
\hline $2 \%$ & - & $0.40 \pm 0.15$ & - & $25.85 \pm 2.63$ & $73.75 \pm 2.68$ \\
\hline - & $2 \%$ & - & $0.32 \pm 0.14$ & $25.71 \pm 2.19$ & $73.97 \pm 2.24$ \\
\hline $2 \%$ & $2 \%$ & $0.36 \pm 0.20$ & $0.36 \pm 0.08$ & $24.03 \pm 4.13$ & $75.25 \pm 4.20$ \\
\hline $4 \%$ & $4 \%$ & $0.75 \pm 0.01$ & $0.84 \pm 0.02$ & $26.27 \pm 3.46$ & $72.14 \pm 3.46$ \\
\hline
\end{tabular}

${ }^{a}$ The EDS values were obtained by elemental analysis from three different spatial locations and are presented as the average and the standard deviation values. ${ }^{b}$ The nominal doping extent values were calculated with respect to the amount of tetra $\left(n\right.$-butyl)titanate. ${ }^{c}$ The atomic percent values from EDS were reported such that the sum of corresponding values of titanium, appropriate lanthanide and oxygen adds to 100. 

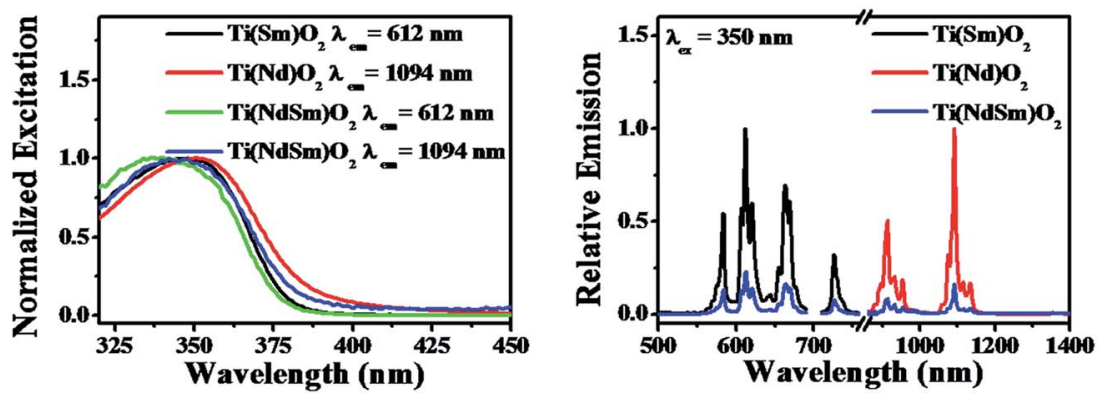

Fig. 5 Photoluminescence excitation (left panel) and emission (right panel) spectra of the $\mathrm{Ti}(\mathrm{Nd}) \mathrm{O}_{2}, \mathrm{Ti}(\mathrm{Sm}) \mathrm{O}_{2}$ and Ti( $(\mathrm{NdSm}) \mathrm{O}_{2}$ nanoparticles are shown. In the right panel, the spectra for the singly doped nanoparticles have been normalized to unity, with the spectrum for the co-doped nanoparticles represented with respect to the singly doped spectra.

by direct excitation of $\mathrm{Ln}^{3+}$ moieties, the Stokes shift is large; thereby virtually eliminating the self quenching. Monitoring either the $\mathrm{Nd}^{3+}$ or $\mathrm{Sm}^{3+}$ emission at 1094 and $612 \mathrm{~nm}$ respectively in the $\mathrm{Ti}(\mathrm{NdSm}) \mathrm{O}_{2}$ nanoparticles, the excitation profiles appear very similar to that obtained in the two singly doped nanoparticles, demonstrating the operation of an optical antenna effect in the co-doped nanoparticles as well.

However, it is important to note that both the $\mathrm{Nd}^{3+}$ and $\mathrm{Sm}^{3+}$ emission decreases in the $\mathrm{Ti}(\mathrm{NdSm}) \mathrm{O}_{2}$ nanoparticles, compared to the corresponding cases in either the $\mathrm{Ti}(\mathrm{Nd}) \mathrm{O}_{2}$ or $\mathrm{Ti}(\mathrm{Sm}) \mathrm{O}_{2}$ nanoparticles. Moreover, this decrease was found to be uneven in the two cases. That is while the $\mathrm{Nd}^{3+}$ emission decreased by $\sim 6$ times in the $\mathrm{Ti}(\mathrm{NdSm}) \mathrm{O}_{2}$ system compared to that in the $\mathrm{Ti}(\mathrm{Nd}) \mathrm{O}_{2}$ nanoparticles, the corresponding decrease for the $\mathrm{Sm}^{3+}$ emission was $\sim 4.5$ times. The efficiency of the lanthanide emission has been compared by the emission quantum yield values and is summarized in Table 2. To shed light on the photophysical behavior, competitive mechanisms with regard to spectral overlap mediated energy transfer formulations (Förster and Dexter) ${ }^{69,70}$ and cation exchange ${ }^{71-76}$ has been considered. Important information regarding the cation exchange mechanism comes from the elemental composition (Table 1). The values related to $\mathrm{Nd}^{3+}$ and $\mathrm{Sm}^{3+}$ dopant incorporation were found to be very similar in the singly doped $\mathrm{Ti}(\mathrm{Ln})$ $\mathrm{O}_{2}[\mathrm{Ln}=\mathrm{Nd}, \mathrm{Sm}]$ and doubly doped $\mathrm{Ti}(\mathrm{NdSm}) \mathrm{O}_{2}$ nanoparticles, suggesting the incorporation of both $\mathrm{Nd}^{3+}$ and $\mathrm{Sm}^{3+}$ is noncompetitive during the formation of the $\mathrm{Ti}(\mathrm{NdSm}) \mathrm{O}_{2}$ nanoparticles. Hence, the inter-lanthanide cation exchange does not play significant contribution in the $\mathrm{Ti}(\mathrm{NdSm}) \mathrm{O}_{2}$ nanoparticles studied. A case where cation exchange being operative during

Table 2 Photoluminescence quantum yield values of the different systems studied ${ }^{a}$

\begin{tabular}{lll}
\hline System & $\Phi_{\mathrm{Nd}^{3+}}$ & $\Phi_{\mathrm{Sm}^{3+}}$ \\
\hline $\mathrm{Ti}(\mathrm{Nd}) \mathrm{O}_{2}$ & $(9.1 \pm 0.2) \times 10^{-2}$ & - \\
$\mathrm{Ti}(\mathrm{Sm}) \mathrm{O}_{2}$ & - & $(2.3 \pm 0.5) \times 10^{-2}$ \\
$\mathrm{Ti}(\mathrm{NdSm}) \mathrm{O}_{2}$ & $(1.5 \pm 0.2) \times 10^{-2}$ & $(0.53 \pm 0.10) \times 10^{-2}$
\end{tabular}

${ }^{a}$ The values have been obtained from three independent measurements and are reported as the average and standard deviation values. the formation of the co-doped nanoparticles; the relative concentration of the displaced lanthanide cation would have been lesser. Accordingly, the observed difference in photoluminescence properties of the $\mathrm{Ti}(\mathrm{NdSm}) \mathrm{O}_{2}$ compared to that in the individually doped $\mathrm{Ti}(\mathrm{Ln}) \mathrm{O}_{2}[\mathrm{Ln}=\mathrm{Nd}, \mathrm{Sm}]$ nanoparticles has predominant origin that is electronic in nature.

Successful incorporation of $\mathrm{Ln}^{3+}$ in core sites of the $\mathrm{Ti}(\mathrm{Ln}) \mathrm{O}_{2}$ nanoparticles studied in the present work comes from the excitation spectra upon monitoring the $\mathrm{Ln}^{3+}$ emission (Fig. 5 and 8), where the excitation profiles devoid of any direct sharp bands and photoluminescence lifetime measurements. The photoluminescence lifetime values for $\mathrm{Sm}^{3+}$ (taken as a representative $\left.\mathrm{Ln}^{3+}\right)$ in the $\mathrm{Ti}(\mathrm{Sm}) \mathrm{O}_{2}$ and $\mathrm{Ti}(\mathrm{NdSm}) \mathrm{O}_{2}$ nanoparticles reveal a bi-exponential decay kinetics (Table 3), where the two lifetime components have been correlated to the lesser protected hence more quenching prone surface relates sites and more protected hence lesser quenching prone core related sites. Similar bi-exponential decay kinetics for $\mathrm{Eu}^{3+}$ emission in $\mathrm{Ti}(\mathrm{Eu}) \mathrm{O}_{2}$ nanoparticles has been reported by van Veggel and coworkers. ${ }^{33}$ It is important to note that $\mathrm{Sm}^{3+}$ has much shorter photoluminescence lifetime in either freely floating form ${ }^{47}$ or in protected molecular complex. ${ }^{\mathbf{1 9}}$

Photophysical rationalization. It is imperative under the spectral overlap mediated inter $\mathrm{Ln}^{3+}$ energy transfer formulations that the realization of decrease of $\mathrm{Nd}^{3+}$ emission compared to that in the singly doped nanoparticles could be hypothecated by an energy transfer from $\mathrm{Nd}^{3+}$ to $\mathrm{Sm}^{3+}$ moieties in the $\mathrm{Ti}(\mathrm{NdSm}) \mathrm{O}_{2}$ nanoparticles. However, such an energy transfer being operative is unable to explain the decrease in the $\mathrm{Sm}^{3+}$ emission in the $\mathrm{Ti}(\mathrm{NdSm}) \mathrm{O}_{2}$ compared to that in the $\mathrm{Ti}(\mathrm{Sm}) \mathrm{O}_{2}$ nanoparticles. Moreover, $\mathrm{Nd}^{3+}$ and $\mathrm{Sm}^{3+}$ emit predominantly in the NIR and visible spectral window. Accordingly, a spectral overlap mechanism being operative would require an upconverted emission, while we do not expect such process to be operative with the experimental conditions used in the present study. Hence, we conclude that the spectral overlap mediated interaction between $\mathrm{Nd}^{3+}$ and $\mathrm{Sm}^{3+}$ in the $\mathrm{Ti}(\mathrm{NdSm}) \mathrm{O}_{2}$ is not a good predictor for the observed trend in the $\mathrm{Nd}^{3+}$ and $\mathrm{Sm}^{3+}$ emission in the co-doped nanoparticles.

Our previous works on the photophysical processes in the $\mathrm{Ti}(\mathrm{Ln}) \mathrm{O}_{2}$ (ref. 46) [Ln = Pr, Nd, Sm, Eu, Gd, Tb, Dy, Ho, Er, Tm, $\mathrm{Yb}]$ and other semiconductor nanoparticles $[\mathrm{Zn}(\mathrm{Ln}) \mathrm{S} ; \mathrm{Ln}=\mathrm{Sm}$, 
Table 3 Photoluminescence lifetime values of the different systems studied

\begin{tabular}{llllll}
\hline System & $a_{1}$ & $\tau_{1}(\mathrm{~ms})$ & $a_{2}$ & $\tau_{2}(\mathrm{~ms})$ & $\langle\tau\rangle^{a}(\mathrm{~ms})$ \\
\hline $\mathrm{Ti}(\mathrm{Sm}) \mathrm{O}_{2}$ & $0.82 \pm 0.02$ & $0.42 \pm 0.01$ & $0.18 \pm 0.02$ & $3.4 \pm 0.3$ & $0.96 \pm 0.11$ \\
$\mathrm{Ti}(\mathrm{NdSm}) \mathrm{O}_{2}$ & $0.76 \pm 0.02$ & $0.53 \pm 0.02$ & $0.24 \pm 0.02$ & $3.6 \pm 0.4$ & $1.27 \pm 0.19$ \\
$\mathrm{Ti}(\mathrm{Eu}) \mathrm{O}_{2}{ }^{c}$ & 0.23 & 0.40 & 0.77 & 1.2 & 0.98 \\
$\mathrm{Ti}(\mathrm{Sm}) \mathrm{O}_{2}{ }^{d}$ & & & & - & 0.97 \\
$\mathrm{Sm}(\mathrm{III}) \mathrm{Ac}^{e}$ & 1.0 & 0.0048 & - & & 0.0048 \\
{$[\mathrm{SmR}(+) \mathrm{BnMeH2} 2 \mathrm{IAM}]^{f}$} & & & & $0.017 \pm 0.002$
\end{tabular}

${ }^{a}\langle\tau\rangle=a_{1} \tau_{1}+a_{2} \tau_{2}$, with $\tau_{1}$ and $\tau_{2}$ being the two lifetime components having relative amplitudes of $a_{1}$ and $a_{2}$ respectively. ${ }^{b}$ The adjusted $R^{2}$ value considers the degrees of freedom during the fitting process and could be used as a gauge to determine the goodness of the fit. ${ }^{c}$ From ref. $33 .{ }^{d}$ From ref. $67 .{ }^{e}$ From ref. $47 .{ }^{f}$ From ref. 19 , where H22IAM is the ligand.

$\mathrm{Eu}, \mathrm{Tb}, \mathrm{Dy}]^{38,44} \mathrm{Zn}(\mathrm{Tb}) \mathrm{S}, \mathrm{Cd}(\mathrm{Tb}) \mathrm{S}, \mathrm{Zn}(\mathrm{Tb}) \mathrm{Se}$ and $\mathrm{Cd}(\mathrm{Tb}) \mathrm{Se}^{38}$ $\mathrm{Zn}(\mathrm{Tb}) \mathrm{S}$ with varying size; ${ }^{43}$ near band gap matched $\mathrm{Sn}(\mathrm{Ln}) \mathrm{O}_{2}$ and $\mathrm{Zn}(\mathrm{Ln}) \mathrm{S}[\mathrm{Ln}=\mathrm{Sm}, \mathrm{Tb}]^{47}$ have been rationalized considering the $\mathrm{Ln}^{3+}$ as the charge traps in the semiconductor nanoparticles and the exciton recombination at the $\mathrm{Ln}^{3+}$ related trap sites resulting in populating the $\mathrm{Ln}^{3+}$ luminescent energy levels, hence realizing the host sensitized $\mathrm{Ln}^{3+}$ luminescence from the doped nanoparticles. Construction of such relative energy level schematics where the $\mathrm{Ln}^{3+}$ ground and excited energy levels are placed with respect to the valence and conduction bands of the host material has been made following a method proposed by Dorenbos. ${ }^{77,78}$ This model relies on two fundamental assumptions, (i) the $4 \mathrm{f}$ binding energies of $\mathrm{Ln}^{3+}$ being universal and is system independent, by virtue of the core like nature of the $4 \mathrm{f}$ electrons and (ii) the energy of charge transfer from the anion valence band to the $\mathrm{Eu}^{3+}$ is equal to the difference in energy between the valence band and the $\mathrm{Eu}^{2+}$ ground energy level. An energy difference between $\mathrm{Eu}^{2+}$ and $\mathrm{Eu}^{3+}$ ground energy level has been considered as $5.7 \mathrm{eV}$ for low band gap material (like the cases of $\mathrm{TiO}_{2}$ nanoparticles). The entire relative energy level schematics can be constructed using these inputs. The corresponding Jablonski diagrams for the $\mathrm{Ti}(\mathrm{Nd}) \mathrm{O}_{2}, \mathrm{Ti}(\mathrm{Sm}) \mathrm{O}_{2}$ and $\mathrm{Ti}(\mathrm{NdSm}) \mathrm{O}_{2}$ nanoparticles are shown in Fig. 6, with the associated photophysical processes discussed in the following text.

In the $\mathrm{Ti}(\mathrm{Nd}) \mathrm{O}_{2}$ nanoparticles, absorption of light around $350 \mathrm{~nm}$ results in an excited electron in the conduction band while leaving a hole in the valence band. The ${ }^{4} I_{9 / 2}$ and ${ }^{4} F_{3 / 2}$ are being placed optimally above and below the valence and conduction band respectively resulting in potential hole and electron trapping in the $\mathrm{Nd}^{3+}$ ground and luminescent energy levels. Such a co-localization of charge carriers in the $\mathrm{Nd}^{3+}$ related trap site within a short time following the initial excitation competes with the time scale of other non-radiative decay mechanisms effectively and exciton recombination in the $\mathrm{Nd}^{3+}$ trap site resulting in the population of the luminescent energy level ${ }^{4} \mathrm{~F}_{3 / 2}$ in the $\mathrm{Ti}(\mathrm{Nd}) \mathrm{O}_{2}$ nanoparticles, thereby realizing the $\mathrm{Nd}^{3+}$ photoluminescence from the doped nanoparticles. Similarly, in the $\mathrm{Ti}(\mathrm{Sm}) \mathrm{O}_{2}$ nanoparticles, the corresponding energy levels ${ }^{6} \mathrm{H}_{5 / 2}$ and ${ }^{4} \mathrm{G}_{5 / 2}$ are responsible for the hole and electron trapping respectively, with the exciton recombination at the $\mathrm{Sm}^{3+}$ trap site resulting the population of ${ }^{4} \mathrm{G}_{5 / 2}$ energy level, thereby generating $\mathrm{Sm}^{3+}$ photoluminescence from the $\mathrm{Ti}(\mathrm{Sm}) \mathrm{O}_{2}$ nanoparticles.
The case where both $\mathrm{Nd}^{3+}$ and $\mathrm{Sm}^{3+}$ are co-doped in the $\mathrm{Ti}(\mathrm{NdSm})_{2}$ nanoparticles, the situation is complex as the interaction between the inter $\mathrm{Ln}^{3+}$ energy levels requires consideration. A visual inspection reveals that the $\mathrm{Nd}^{3+}$ ground energy level ${ }^{4} \mathrm{I}_{9 / 2}$ lies above the corresponding level of $\mathrm{Sm}^{3+}{ }^{6} \mathrm{H}_{5 / 2}$. Similar consideration on the luminescent energy level shows that the $\mathrm{Sm}^{3+}{ }^{4} \mathrm{G}_{5 / 2}$ lies above the corresponding $\mathrm{Nd}^{3+}{ }^{4} \mathrm{~F}_{3 / 2}$ energy level. These energy levels predict that the initially trapped hole and electron at the $\mathrm{Sm}^{3+}$ related trap should subsequently populate the $\mathrm{Nd}^{3+}$ energy levels. Accordingly, one might
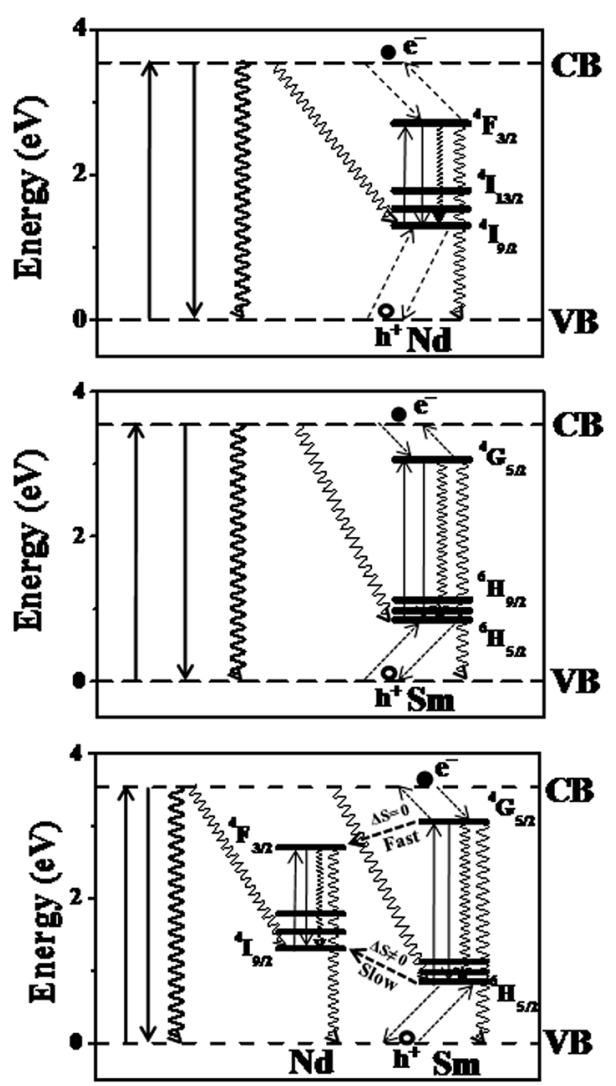

Fig. 6 The Jablonski diagrams for the $\mathrm{Ti}(\mathrm{Nd}) \mathrm{O}_{2}, \mathrm{Ti}(\mathrm{Sm}) \mathrm{O}_{2}$ and $\mathrm{Ti}(\mathrm{NdSm}) \mathrm{O}_{2}$ nanoparticles are shown, with the identification of key photophysical processes. The dashed arrows represent the charge trapping and detrapping processes. The downward solid and squiggly arrows represent the radiative and non-radiative recombination processes respectively. 
expect that the $\mathrm{Nd}^{3+}$ emission should enhance at the expense of $\mathrm{Sm}^{3+}$ emission in the $\mathrm{Ti}(\mathrm{NdSm}) \mathrm{O}_{2}$ nanoparticles, compared to the singly doped $\mathrm{Ti}(\mathrm{Nd}) \mathrm{O}_{2}$ and $\mathrm{Ti}(\mathrm{Sm}) \mathrm{O}_{2}$ nanoparticles respectively. Experimentally however this was not observed, where both the $\mathrm{Nd}^{3+}$ and $\mathrm{Sm}^{3+}$ emission decreases in the doubly doped nanoparticles compared to that in the singly doped counterparts, with the decrease being marginally more prominent in $\mathrm{Nd}^{3+}$ compared to that for the $\mathrm{Sm}^{3+}$ emission. This trend clearly indicate competitive role being operative.

We propose that the relaxation of the initially trapped charge carriers at the $\mathrm{Sm}^{3+}$ trap sites relax following the spin $(S)$ selection rule, which states the transition is more favorable and fast when $\Delta S=0$. This means while the initially trapped electron from $\mathrm{Sm}^{3+}$ trap site is able to relax to the $\mathrm{Nd}^{3+}$ luminescent energy level within a short time that essentially competes with the depopulation of the $\mathrm{Sm}^{3+}$ luminescence, the situation is not same for the hole trapping case. As the spin quantum number is changing in the $\mathrm{Sm}^{3+}$ and $\mathrm{Nd}^{3+}$ ground energy levels, the hole trapping from the $\mathrm{Sm}^{3+}$ related site to the $\mathrm{Nd}^{3+}$ ground energy level is inefficient and a slow process and essentially is not complete within the excited state lifetime of $\mathrm{Sm}^{3+}$ in the $\mathrm{Ti}(\mathrm{NdSm}) \mathrm{O}_{2}$ nanoparticles. At this point, it is important to note that while the exciton recombination at the $\mathrm{Ln}^{3+}$ trap site with co-localization of hole and electron in the $\mathrm{Ln}^{3+}$ ground and luminescent energy levels would be the most efficient way to populate the luminescent energy level of the $\mathrm{Ln}^{3+}$ in host semiconductor nanoparticles, other related lesser efficient nonradiative recombination processes include the recombination of electron and hole at the valence and conduction band of the host lattice or electron and hole at the conduction band and the $\mathrm{Ln}^{3+}$ ground energy level or electron and hole at the $\mathrm{Ln}^{3+}$ luminescent energy level and valence band of the host lattice respectively. Such a photophysical rationalization with initial charge trapping in the $\mathrm{Sm}^{3+}$ trap site and subsequent fast relaxation of the excited electron from the $\mathrm{Sm}^{3+}$ to $\mathrm{Nd}^{3+}$ energy level and associated slow trapping of photo-generated hole from the $\mathrm{Sm}^{3+}$ to $\mathrm{Nd}^{3+}$ (that essentially competes with the microseconds to milliseconds lifetime of $\mathrm{Sm}^{3+}$ in the $\mathrm{TiO}_{2}$ based nanoparticles) accounts for the quenching of both $\mathrm{Nd}^{3+}$ and $\mathrm{Sm}^{3+}$ photoluminescence in the co-doped nanoparticles, compared to the corresponding nanoparticles with a single dopant moiety. Moreover, we anticipate that the slightly lesser quenching of the $\mathrm{Sm}^{3+}$ luminescence (compared to the case with $\mathrm{Nd}^{3+}$ ) in the $\mathrm{Ti}(\mathrm{NdSm}) \mathrm{O}_{2}$ nanoparticles, compared to that in the $\mathrm{Ti}(\mathrm{Sm}) \mathrm{O}_{2}$ nanoparticles, most likely associate with the initial trapping of the charge carriers at the $\mathrm{Sm}^{3+}$ sites and the initiation of subsequent exciton recombination, while such a process at the $\mathrm{Nd}^{3+}$ site experiences competitive relaxation processes and essentially would be lesser efficient.

To check this hypothesis that the experimental observations in the co-doped $\mathrm{Ti}(\mathrm{NdSm}) \mathrm{O}_{2}$ nanoparticles relate with the inter $\mathrm{Ln}^{3+}$ relaxation pathways that is dictated by the spin selection rule, we have undertaken experiments with $\mathrm{Nd}^{3+}$ and $\mathrm{Er}^{3+}$ codoped $\mathrm{TiO}_{2}\left[\mathrm{Ti}(\mathrm{NdEr}) \mathrm{O}_{2}\right]$ nanoparticles. This combination of $\mathrm{Ln}^{3+}$ offers the access of ground and luminescent energy levels with $\Delta S=0$. The Jablonski diagram for the $\mathrm{Ti}(\mathrm{NdEr}) \mathrm{O}_{2}$ nanoparticles is shown in Fig. 7. However, $\mathrm{Er}^{3+}$ has more than one

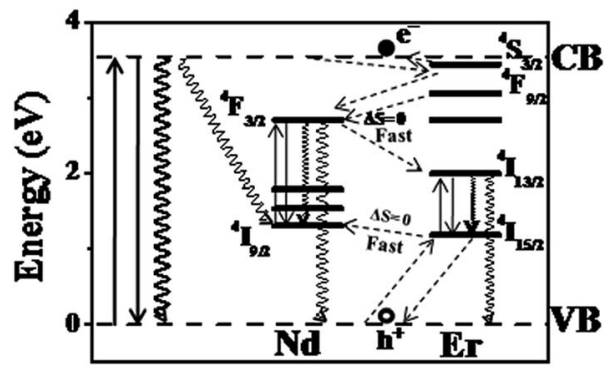

Fig. 7 The Jablonski diagram for the $\mathrm{Ti}(\mathrm{NdEr}) \mathrm{O}_{2}$ nanoparticles is shown.

major luminescent energy levels and essentially the position of a particular luminescent energy level with respect to the conduction band of the host $\mathrm{TiO}_{2}$ nanoparticles matter while considering the $\mathrm{Er}^{3+}$ luminescence properties. The ${ }^{4} \mathrm{~S}_{3 / 2}$ and ${ }^{4} \mathrm{~F}_{9 / 2}$ energy levels of $\mathrm{Er}^{3+}$ lie above the $\mathrm{Nd}^{3+}{ }^{4} \mathrm{~F}_{3 / 2}$ energy level, suggesting efficient electron relaxation from the $\mathrm{Er}^{3+}$ to $\mathrm{Nd}^{3+}$ in the $\mathrm{Ti}(\mathrm{NdEr}) \mathrm{O}_{2}$ nanoparticles. This however opens another possibility of relaxation from $\mathrm{Nd}^{3+4} \mathrm{~F}_{3 / 2}$ to $\mathrm{Er}^{3+}{ }^{3} \mathrm{I}_{13 / 2}$ energy level. On the other hand, the initially trapped hole at the $\mathrm{Er}^{3+}{ }^{4} \mathrm{I}_{15 / 2}$ has capability to get trapped at the $\mathrm{Nd}^{3+}{ }^{4} \mathrm{I}_{9 / 2}$ energy level, with significant back hole transfer as these energy levels are nearly isoenergetic.

The photoluminescence excitation and emission spectra of the $\mathrm{Ti}(\mathrm{NdEr}) \mathrm{O}_{2}$ nanoparticles are shown in Fig. 8. The relevant quantum yield values are summarized in Table 4 . Clearly the emission at 565 and $665 \mathrm{~nm}$ originating from ${ }^{4} \mathrm{~S}_{3 / 2} \rightarrow{ }^{4} \mathrm{I}_{15 / 2}$ and ${ }^{4} \mathrm{~F}_{9 / 2} \rightarrow{ }^{4} \mathrm{I}_{15 / 2}$ respectively diminishes in the co-doped Ti(NdEr) $\mathrm{O}_{2}$ nanoparticles, compared to that in the $\mathrm{Ti}(\mathrm{Er}) \mathrm{O}_{2}$ nanoparticles. On the other hand, the emission intensity of $1550 \mathrm{~nm}$ band originating from ${ }^{4} \mathrm{I}_{13 / 2} \rightarrow{ }^{4} \mathrm{I}_{15 / 2}$ increases by $\sim 3$ times in the doubly doped nanoparticles, compared to that in the singly $\mathrm{Er}^{3+}$ doped counterpart. The increase in $\mathrm{Er}^{3+}$ emission around $1550 \mathrm{~nm}$ in presence of $\mathrm{Nd}^{3+}$ is consistent with the electron relaxation from the ${ }^{4} \mathrm{~F}_{3 / 2}$ energy level of $\mathrm{Nd}^{3+}$ to the $\mathrm{Er}^{3+}{ }^{4} \mathrm{I}_{13 / 2}$ energy level. Moreover, the excitation spectrum monitoring the $\mathrm{Er}^{3+} 1550 \mathrm{~nm}$ emission in the $\mathrm{Ti}(\mathrm{NdEr}) \mathrm{O}_{2}$ nanoparticles also has contribution from host sensitized photoluminescence.

The excitation spectra upon monitoring the $\mathrm{Ln}^{3+}$ emission in either the singly or doubly $\mathrm{Ln}^{3+}$ incorporated nanoparticles investigated in the present work only reveal a broad profile that is related to host sensitization, without noticeable contribution from the direct sharp intra-configurational excitation bands. The inability to observe such direct excitation bands most likely associate with the following points; (i) an estimation of the concentration of $\mathrm{Ln}^{3+}$ in the nanoparticles used in the photoluminescence spectroscopy measurements result in a value of $\leq 35$ micromolar which is too low to observe extremely inefficient direct excitation, in presence of stronger contribution from host sensitization. It is noteworthy that van Veggel ${ }^{33}$ reported direct excitation bands in the $\mathrm{Ti}(\mathrm{Ln}) \mathrm{O}_{2}[\mathrm{Ln}=\mathrm{Nd}, \mathrm{Er}]$ excitation profiles only when the nanoparticles concentration was high, whereas the same system with lower concentration of the nanoparticles did not produce the sharp lines in the excitation profile, (ii) in the framework of charge trapping mediated 

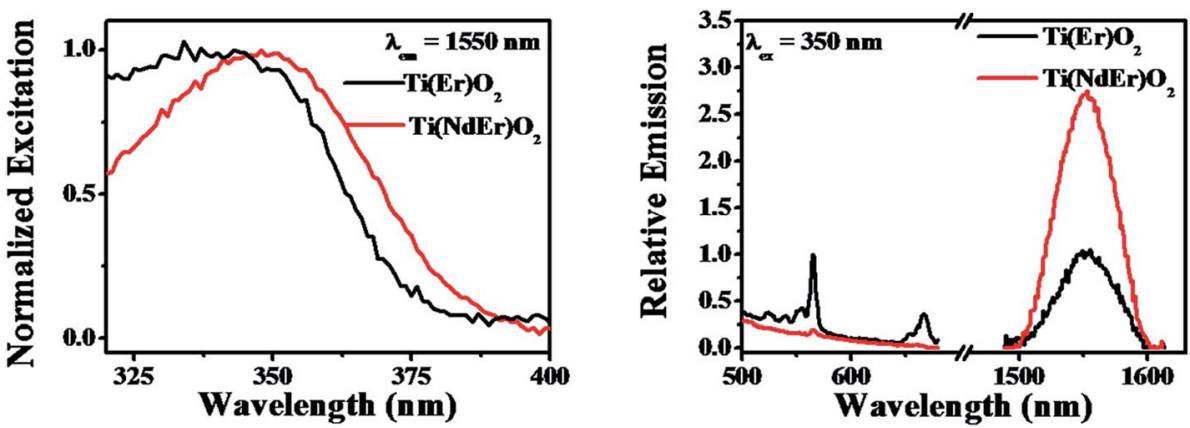

Fig. 8 Photoluminescence excitation (left panel) and emission (right panel) spectra of the $\mathrm{Ti}(\mathrm{Nd}) \mathrm{O}_{2}, \mathrm{Ti}(\mathrm{Er}) \mathrm{O}_{2}$ and $\mathrm{Ti}(\mathrm{NdEr}) \mathrm{O}_{2}$ nanoparticles are shown. In the right panel, the emission intensity of the singly doped nanoparticles has been normalized to unity, with the intensity in the codoped nanoparticles represented with respect to the singly doped system.

Table 4 Photoluminescence quantum yield values of the different systems studied ${ }^{a}$

\begin{tabular}{llll}
\hline System & $\Phi_{\mathrm{Nd}^{3+}}$ & $\Phi_{\mathrm{Er}^{3+}}\left[{ }^{4} \mathrm{~S}_{3 / 2} \rightarrow{ }^{4} \mathrm{I}_{15 / 2}\right]+\Phi_{\mathrm{Er}^{3+}\left[{ }^{4} \mathrm{~F}_{3 / 2} \rightarrow{ }^{4} \mathrm{I}_{15 / 2}\right]}$ & - \\
\hline $\mathrm{Ti}(\mathrm{Nd}) \mathrm{O}_{2}$ & $(9.1 \pm 0.2) \times 10^{-2}$ & - & $(0.60 \pm 0.14) \times 10^{-6}$ \\
$\mathrm{Ti}(\mathrm{Er}) \mathrm{O}_{2}$ & - & $(1.9 \pm 1.0) \times 10^{-5}$ & $(1.63 \pm 0.17) \times 10^{-6}$
\end{tabular}

${ }^{a}$ The values have been obtained from two independent measurements and are reported as the average and standard deviation values.

photoluminescence sensitization mechanism some of the $\mathrm{Ln}^{3+}$ energy levels lie closer or above the conduction band of the host lattice suggesting rapid autoionization of charge carriers. However, we note that in cases where sensitization involves an inter band gap $\mathrm{Ln}^{3+}$ energy level, a red shifted broad profile may result. Such scenario may arise in the $\mathrm{Ti}(\mathrm{NdEr}) \mathrm{O}_{2}$ nanoparticles, where the excitation spectrum upon monitoring the $\mathrm{Er}^{3+}$ emission at $1550 \mathrm{~nm}$ result in an enhanced lower energy contribution compared to that in the $\mathrm{Ti}(\mathrm{Er}) \mathrm{O}_{2}$ nanoparticles.

Finally, we note that while the photophysical rationalization presented in this work provides a qualitative basis to visualize the experimental observations, a complete picture requires the characterization of entire dynamics involving a wide range of time scales, with the charge trapping might be occurring in few picoseconds, ${ }^{79}$ nanoparticles and $\mathrm{Ln}^{3+}$ population decay occurring in the nanoseconds to microseconds-milliseconds range. ${ }^{5,38}$

\section{Conclusions}

Guided by the unique luminescence properties of the trivalent lanthanide cations $\left(\mathrm{Ln}^{3+}\right)$ with its potential usefulness as multiplex assays and our recent work on singly $\mathrm{Ln}^{3+}$ doped titanium dioxide $\left[\mathrm{Ti}(\mathrm{Ln}) \mathrm{O}_{2}\right]$ nanoparticles with the identification of $\mathrm{Ti}(\mathrm{Nd}) \mathrm{O}_{2}$ and $\mathrm{Ti}(\mathrm{Sm}) \mathrm{O}_{2}$ as the most promising systems having host sensitized dopant photoluminescence, this study develops a system where $\mathrm{Nd}^{3+}$ and $\mathrm{Sm}^{3+}$ have been co-doped in the $\mathrm{TiO}_{2}$ nanoparticles, to synthesize the $\mathrm{Ti}(\mathrm{NdSm}) \mathrm{O}_{2}$ nanoparticles. The co-doped nanoparticles benefits from simultaneous $\mathrm{Sm}^{3+}$ visible emission at 584, 612, 664 and $726 \mathrm{~nm}$ respectively and $\mathrm{Nd}^{3+}$ near infrared (NIR) emission at 912 and $1094 \mathrm{~nm}$ respectively. This provides an avenue to realize six distinct and non-overlapping emission bands spanning the orange-red and NIR spectral window using a single excitation wavelength, with a large Stokes shift. A comparison between the doubly doped and the corresponding singly doped nanoparticles reveals significant differences, with the $\mathrm{Nd}^{3+}$ and $\mathrm{Sm}^{3+}$ emission decreasing by $\sim 6$ and $\sim 4.5$ times in the co-doped system compared to that in the singly doped nanoparticles. The results have been rationalized considering the $\mathrm{Ln}^{3+}$ acting as charge traps in the semiconductor nanoparticles and associated inter $\mathrm{Ln}^{3+}$ (applicable in the codoped nanoparticles) relaxation pathways that are governed by the spin selection rule. This proposed rationalization has been tested and verified by performing experiments with the Ti(NdEr) $\mathrm{O}_{2}$ nanoparticles, in which $1550 \mathrm{~nm}$ emission of $\mathrm{Er}^{3+}$ has been increased in intensity in the co-doped nanoparticles by $\sim 3$ times, compared to that in the $\mathrm{Ti}(\mathrm{Er}) \mathrm{O}_{2}$ nanoparticles. To summarize, this work provides an avenue to develop a multiplex assay using $\mathrm{Sm}^{3+}$ and $\mathrm{Nd}^{3+}$ emission in the orange-red and NIR spectral range respectively. Future works may focus on developing composite doped nanoparticles having host sensitized dopant emission with distinct non-overlapping bands spanning the entire visible (blue, green and red) and NIR spectral domain simultaneously. The photophysical aspects discussed in the current work provides valuable foundation for developing such a composite system.

\section{Conflicts of interest}

There are no conflicts to declare.

\section{Acknowledgements}

Financial assistance from the Science and Engineering Research Board (SERB), Department of Science and Technology 
(DST) (SB/S1/PC-040/2013) is gratefully acknowledged. The authors thank Ms Urmila Goswami and Mr Prothyush Sengupta for help in the electron microscopy measurements. The authors also thank Prof. Dipankar Chattopadhyay for letting us use the XRD instrument in his laboratory and Mr Nayan Ranjan Saha for helping us with the XRD measurements.

\section{References}

1 J.-C. G. Bünzli and C. Piguet, Chem. Soc. Rev., 2005, 34, 10481077.

2 E. G. Moore, A. P. S. Samuel and K. N. Raymond, Acc. Chem. Res., 2009, 42, 542-552.

3 J.-C. G. Bünzli, Acc. Chem. Res., 2006, 39, 53-61.

4 S. V. Eliseeva and J.-C. G. Bünzli, Chem. Soc. Rev., 2010, 39, 189-227.

5 J.-C. G. Bünzli, Chem. Rev., 2010, 110, 2729-2755.

6 K. Binnemans, Chem. Rev., 2009, 109, 4283-4374.

7 C. P. Montgomery, B. S. Murray, E. J. New, R. Pal and D. Parker, Acc. Chem. Res., 2009, 42, 925-937.

8 N. Hildebrandt and H.-G. Löhmannsröben, Curr. Chem. Biol., 2007, 1, 167-186.

9 A. Thibon and V. C. Pierre, Anal. Bioanal. Chem., 2009, 394, 107-120.

10 M. A. Alcala, S. Y. Kwan, C. M. Shade, M. Lang, H. Uh, M. Wang, S. G. Weber, D. L. Bartlett, S. Petoud and Y. J. Lee, Nanomedicine, 2011, 7, 249-258.

11 F. Wang and X. Liu, Chem. Soc. Rev., 2009, 38, 976-989.

12 W. Zheng, P. Huang, D. Tu, E. Ma, H. Zhu and X. Chen, Chem. Soc. Rev., 2015, 44, 1379-1415.

13 C. Bouzigues, T. Gacoin and A. Alexandrou, ACS Nano, 2011, 5, 8488-8505.

14 R. D. Teo, J. Termini and H. B. Gray, J. Med. Chem., 2016, 59, 6012-6024.

15 A. K. Hagan and T. Zuchner, Anal. Bioanal. Chem., 2011, 400, 2847-2864.

16 M. Sy, A. Nonat, N. Hildebrandt and L. J. Charbonnière, Chem. Commun., 2016, 52, 5080-5095.

17 A. Beeby, I. M. Clarkson, R. S. Dickins, S. Faulkner, D. Parker, L. Royle, A. S. de Sousa, J. A. G. Williams and M. Woods, J. Chem. Soc., Perkin Trans. 2, 1999, 493-503.

18 J.-C. G. Bünzli, Coord. Chem. Rev., 2015, 293-294, 19-47.

19 S. Petoud, G. Muller, E. G. Moore, J. Xu, J. Sokolnicki, J. P. Riehl, U. N. Le, S. M. Cohen and K. N. Raymond, J. Am. Chem. Soc., 2007, 129, 77-83.

20 H. Uh and S. Petoud, C. R. Chim., 2010, 13, 668-680.

21 J.-F. Lemonnier, L. Guénée, C. Beuchat, T. A. Wesolowski, P. Mukherjee, D. H. Waldeck, K. A. Gogick, S. Petoud and C. Piguet, J. Am. Chem. Soc., 2011, 133, 16219-16234.

22 J.-F. Lemonnier, L. Babel, L. Guénée, P. Mukherjee, D. H. Waldeck, S. V. Eliseeva, S. Petoud and C. Piguet, Angew. Chem., Int. Ed., 2012, 51, 11302-11305.

23 J. Zhang, C. M. Shade, D. A. Chengelis and S. Petoud, J. Am. Chem. Soc., 2007, 129, 14834-14835.

24 J. P. Cross, M. Lauz, P. D. Badger and S. Petoud, J. Am. Chem. Soc., 2004, 126, 16278-16279.
25 C. S. Bonnet, L. Pellegatti, F. Buron, C. M. Shade, S. Villette, V. Kubiček, G. Guillaumet, F. Suzenet, S. Petoud and É. Tóth, Chem. Commun., 2010, 46, 124-126.

26 K. A. White, D. A. Chengelis, K. A. Gogick, J. Stehman, N. L. Rosi and S. Petoud, J. Am. Chem. Soc., 2009, 131, 18069-18071.

27 K. A. White, D. A. Chengelis, M. Zeller, S. J. Geib, J. Szakos, S. Petoud and N. L. Rosi, Chem. Commun., 2009, 4506-4508.

28 A. Foucault-Collet, K. A. Gogick, K. A. White, S. Villette, A. Pallier, G. Collet, C. Kieda, T. Li, S. J. Geib, N. L. Rosi and S. Petoud, Proc. Natl. Acad. Sci. U. S. A., 2013, 110, 17199-17204.

29 D. A. Chengelis, A. M. Yingling, P. D. Badger, C. M. Shade and S. Petoud, J. Am. Chem. Soc., 2005, 127, 16752-16753.

30 X. Chen, W. Luo, Y. Liu and G. Liu, J. Rare Earths, 2007, 25, 515-525.

31 Y. Liu, D. Tu, H. Zhu and X. Chen, Chem. Soc. Rev., 2013, 42, 6924-6958.

32 W. Luo, Y. Liu and X. Chen, Sci. China Mater., 2015, 1-32.

33 J. W. Stouwdam and F. C. J. M. van Veggel, ChemPhysChem, 2004, 5, 743-746.

34 A. P. Jadhav, A. U. Pawar, U. Pal and Y. S. Kang, J. Mater. Chem. C, 2014, 2, 496-500.

35 A. Pawar, A. Jadhav, C. W. Kim, H. G. Cha, U. Pal and Y. S. Kang, J. Lumin., 2015, 157, 131-136.

36 J. Planelles-Aragó, B. Julián-López, E. Cordoncillo, P. Escribano, F. Pellé, B. Viana and C. Sanchez, J. Mater. Chem., 2008, 18, 5193-5199.

37 J. Planelles-Aragó, E. Cordoncillo, R. A. S. Ferreira, L. D. Carlos and P. Escribano, J. Mater. Chem., 2011, 21, 1162-1170.

38 P. Mukherjee, C. M. Shade, A. M. Yingling, D. N. Lamont, D. H. Waldeck and S. Petoud, J. Phys. Chem. A, 2011, 115, 4031-4041.

39 P. Mukherjee, R. F. Sloan, C. M. Shade, D. H. Waldeck and S. Petoud, J. Phys. Chem. C, 2013, 117, 14451-14460.

40 J. R. Dethlefsen, A. A. Mikhailovsky, P. T. Burks, A. Døssing and P. C. Ford, J. Phys. Chem. C, 2012, 116, 23713-23720.

41 R. Martín-Rodríguez, R. Geitenbeek and A. Meijerink, J. Am. Chem. Soc., 2013, 135, 13668-13671.

42 A. Ghatak, G. H. Debnath, M. Mandal and P. Mukherjee, RSC Adv., 2015, 5, 32920-32932.

43 G. H. Debnath, A. Chakraborty, A. Ghatak, M. Mandal and P. Mukherjee, J. Phys. Chem. C, 2015, 119, 24132-24141.

44 A. Chakraborty, G. H. Debnath, M. Ahir, S. Bhattacharya, P. Upadhyay, A. Adhikary and P. Mukherjee, RSC Adv., 2016, 6, 43304-43315.

45 G. H. Debnath, A. Chakraborty and P. Mukherjee, RSC Adv., 2016, 6, 85230-85241.

46 A. Chakraborty, G. H. Debnath, N. R. Saha, D. Chattopadhyay, D. H. Waldeck and P. Mukherjee, J. Phys. Chem. C, 2016, 120, 23870-23882.

47 P. Manna, A. Chakraborty, G. H. Debnath and P. Mukherjee, J. Phys. Chem. Lett., 2017, 8, 2794-2798.

48 J. R. DiMaio, C. Sabatier, B. Kokuoz and J. Ballato, Proc. Natl. Acad. Sci. U. S. A., 2008, 105, 1809-1813. 
49 K. Murray, Y.-C. Cao, S. Ali and Q. Hanley, Analyst, 2010, 135, 2132-2138.

50 Y. Xu and Q. Li, Clin. Chem., 2007, 53, 1503-1510.

51 L. Cheng, K. Yang, S. Zhang, M. Shao, S. Lee and Z. Liu, Nano Res., 2010, 3, 722-732.

52 H. H. Gorris, R. Ali, S. M. Saleh and O. S. Wolfbeis, Adv. Mater., 2011, 23, 1652-1655.

53 H. Dong, L.-D. Sun, W. Feng, Y. Gu, F. Li and C.-H. Yan, ACS Nano, 2017, 11, 3289-3297.

54 R. Deng and X. Liu, Nat. Photonics, 2014, 8, 10-12.

55 D. Gao, H. Zheng, X. Zhang, W. Gao, Y. Tian, J. Li and M. Cui, Nanotechnology, 2011, 22, 175702.

56 W. Xu, B. A. Bony, C. R. Kim, J. S. Baeck, Y. Chang, J. E. Bae, K. S. Chae, T. J. Kim and G. H. Lee, Sci. Rep., 2013, 3, 3210. 57 S. H. Crayton, D. R. Elias, A. A. Zaki, Z. Cheng and A. Tsourkas, Biomaterials, 2012, 33, 1509-1519.

58 X. Yan, L. Yang and Q. Wang, Angew. Chem., Int. Ed., 2011, 50, 5130-5133.

59 X. Gao, L. Yang, J. A. Petros, F. F. Marshall, J. W. Simons and S. Nie, Curr. Opin. Biotechnol., 2005, 16, 63-72.

60 W. C. Chan, D. J. Maxwell, X. Gao, R. E. Bailey, M. Han and S. Nie, Curr. Opin. Biotechnol., 2002, 13, 40-46.

61 X. Gao and S. Nie, Trends Biotechnol., 2003, 21, 371-373.

$62 \mathrm{M}$. Hu, J. Yan, Y. He, H. Lu, L. Weng, S. Song, C. Fan and L. Wang, ACS Nano, 2010, 4, 488-494.

63 P. Ellmark, L. Belov, P. Huang, C. S. Lee, M. J. Solomon, D. K. Morgan and R. I. Christopherson, Proteomics, 2006, 6, 1791-1802.
64 H. Li, Z. Cao, Y. Zhang, C. Lau and J. Lu, Anal. Methods, 2010, 2, 1236-1242.

65 M. V. Yezhelyev, X. Gao, Y. Xing, A. Al-Hajj, S. Nie and R. M. O'Regan, Lancet Oncol., 2006, 7, 657-667.

66 W. Luo, R. Li, G. Liu, M. R. Antonio and X. Chen, J. Phys. Chem. C, 2008, 112, 10370-10377.

67 W. Luo, R. Li and X. Chen, J. Phys. Chem. C, 2009, 113, 87728777.

68 J. E. Lewis and M. Maroncelli, Chem. Phys. Lett., 1998, 282, 197-203.

69 J. R. Lakowicz, Principles of Fluorescence Spectroscopy, 3rd edn, 2006.

70 S. Speiser, Chem. Rev., 1996, 96, 1953-1976.

71 D. H. Son, S. M. Hughes, Y. Yin and A. P. Alivisatos, Science, 2004, 306, 1009-1012.

72 R. D. Robinson, B. Sadtler, D. O. Demchenko, C. K. Erdonmez, L.-W. Wang and A. P. Alivisatos, Science, 2007, 317, 355-358.

73 D. Mocatta, G. Cohen, J. Schattner, O. Millo, E. Rabani and U. Banin, Science, 2011, 332, 77-81.

74 C. Dong and F. C. J. M. van Veggel, ACS Nano, 2009, 3, 123130.

75 B. J. Beberwyck, Y. Surendranath and A. P. Alivisatos, J. Phys. Chem. C, 2013, 117, 19759-19770.

76 J. B. Rivest and P. K. Jain, Chem. Soc. Rev., 2013, 42, 89-96.

77 P. Dorenbos and E. van der Kolk, Appl. Phys. Lett., 2006, 89, 061122.

78 P. Dorenbos, J. Alloys Compd., 2009, 488, 568-573.

79 P. Kambhampati, J. Phys. Chem. C, 2011, 115, 22089-22109. 